\title{
Accreditation: Wrong Path for the Geosciences
}

Timothy Bralower*, William Easterling, College of Earth and Mineral Sciences, Pennsylvania State Univ., University Park, Pennsylvania 16802, USA; John Geissman, Dept. of Earth and Planetary Sciences, Univ. of New Mexico, Albuquerque, New Mexico 87131, USA; Mary Savina, Dept. of Geology, Carleton College, Northfield, Minnesota 55057, USA; Barbara Tewksbury, Dept. of Geosciences, Hamilton College, Clinton, New York 13323, USA; Geoffrey Feiss, Heather Macdonald, College of William and Mary, Williamsburg, Virginia 23187, USA; and Dallas Rhodes, Dept. of Geology and Geography, Georgia Southern Univ., Statesboro, Georgia 30460, USA

\section{INTRODUCTION: THE "GRAND CHALLENGES"}

Earth scientists are in a unique position to contribute to pressing issues of great societal relevance, from managing water supplies to extending the supply of fossil fuels and other energy sources, mitigating the effects of natural hazards, evaluating environmental health, and predicting and mitigating the consequences of global warming. Geoscience departments have a unique responsibility to address these issues effectively as they educate students, build research programs, and provide outreach and service to society. It is in this light that we examine the potential impact of accreditation of geoscience bachelor degree programs (B.A. and B.S.) now under development by a coalition of professional societies as presented in the September GSA Today (GSA Ad Hoc Committee on Accreditation [GSA ad hoc comm.], 2008).

The potential effects of accreditation on departments and their students would differ depending upon the nature of the accreditation system. Herein, we consider the effects of a moderately formal system comparable to that used by the American Chemical Society: a rigid curriculum, detailed accounting, and review by an external disciplinary board (similar to Model 3 in the GSA survey; GSA ad hoc comm., 2008). Our perspectives on the effects of accreditation come from a variety of institutions: Six of the authors are geoscience faculty and two are university administrators (a dean and a provost) with broad views of other science and engineering fields with accredited degree programs.

We are deeply concerned that national accreditation would have a negative impact on geoscience departments and their missions to educate both future geoscientists and science-literate citizens. These missions can be more effectively accomplished through promoting strong, flexible geoscience departments and professional licensing than by constraining undergraduate geoscience education.

\section{WOULD A STANDARDIZED CURRICULUM BE THE BEST SOLUTION FOR UNDERGRADUATE EDUCATION?}

One of the most important roles of geoscience departments is to train future geoscientists, and the push to accredit geoscience

GSA Today, v. 18, no. 10, doi: 10.1130/GSATG25GW.1

*bralower@psu.edu degrees is, of course, aimed at this role. But is a rigid undergraduate curriculum really the best way to train future geoscientists? Undergraduate geoscience curricula around the country have evolved organically and are characterized both by notable variety (Drummond and Markin, 2008) and long-term success in producing career geoscientists. Most departments have given a great deal of thought to the sequence of core courses and have made decisions that provide students with the best education possible, especially given the local resources available.

What would we lose if we were to standardize the undergraduate core curriculum? For one, we would lose flexibility and innovation. Accreditation restricts departments to matching their curricula to externally imposed standards. Departments would be less likely to innovate for fear of losing accreditation. This has been a significant issue in other disciplines with accredited undergraduate programs, such as chemistry and engineering. At the course level, instructors would feel pressure to "teach to the test," possibly discouraging them from adapting their courses to reflect evolving best practices in higher education.

The National Science Foundation and the National Research Council have continually emphasized the importance at the undergraduate level of developing higher order thinking skills, providing hands-on learning experiences, and applying knowledge to solving problems, rather than simply transmitting content. Accreditation is likely to focus on specific course content at the expense of providing students with opportunities to use their knowledge to solve problems and think critically.

Industry and agencies want employees who can solve problems. Future geoscience graduates must be able to adapt to an ever-broadening range of careers in water, energy, climate policy, resources, land use, and education. A rigidly defined national curriculum would not provide the flexibility necessary to adequately prepare students for these diverse fields. Even careers that are more suited to traditional training (e.g., the extractive industries) are likely to hire increasingly versatile geoscientists as the nature of these industries change.

Geoscience departments also have an opportunity to educate future citizens and professionals in other fields. Not all geoscience majors become career geologists; in fact, most students do not identify a specific career before graduation. Society could benefit enormously if more business people, politicians, and lawyers were trained in geoscience at the undergraduate level. For many of these professions, the choice of undergraduate major is flexible; geoscience departments have a golden opportunity to recruit bright students interested in the Earth. This is unlikely to happen, however, if accreditation requires adoption of a rigid undergraduate curriculum, thereby eliminating the flexibility that is most likely to draw those students.

\section{WOULD ACCREDITATION BE DESIRABLE FOR GEOSCIENCE DEPARTMENTS?}

Many departments are struggling with small numbers of majors, and an alarming number of institutions have closed their geoscience departments. The next decade is likely to be one of fiscal hardship in 
public higher education (National Governors Association and National Association of State Budget Officers, 2008). Geoscience departments have fewer majors than currently accredited fields, and administrators faced with the accreditation costs, especially in providing additional faculty to cover required courses, might target geoscience departments of marginal size or strength for closure.

To thrive, geoscience departments need to attract more majors, develop interdisciplinary programs that better prepare students to tackle societal problems related to the earth sciences, and make themselves more broadly relevant. We are deeply concerned that an accreditation program, with its prescribed curriculum, would not result in a windfall of majors but would actually make it far more difficult for geoscience departments to succeed and grow.

Accreditation is likely to decrease the number of geoscience majors. Geoscience remains a major of discovery, and our ability to accommodate a range of interests has helped the discipline rebound from the sharp enrollment decline that followed the last oil price bust. Many majors choose geology because of their interest in the Earth but make careers in other fields. A rigid, pre-professional curriculum would not serve these students well and would likely redirect them to earth-science-related programs not as prescriptive in curricular design, such as geography and environmental science.

Much of cutting-edge geoscience lies at the interface among disciplines. A rigid accreditation curriculum focusing on traditional geology would hamper interdisciplinary education. By restricting curriculum flexibility, accreditation would also be at odds with attempts to increase enrollment in geoscience departments by focusing on important new areas of study. New degree programs that couple geoscience with other sciences and with public policy, business, and law require flexibility. Many departments, however, are not in a position to develop new degrees and must instead broaden existing bachelor's degree programs; accreditation would hinder such progress.

Geoscience departments have lost clout on campus in part because they have not demonstrated relevance to the larger scientific and societal issues of our time, but our "Grand Challenges" are unrivaled and provide the geosciences with potential for great visibility on campus, among the general public, and with our elected representatives. Adopting a rigid accreditation curriculum focused on traditional geologist preparation will not help departments demonstrate that geoscience is the discipline most relevant to the societal and environmental issues that we face today.

The work involved in achieving and maintaining accreditation is also a major concern. Time spent on instituting procedures, maintaining records, conducting evaluations, and organizing reviews would draw on time used to innovate and improve course quality.

\section{WOULD ACCREDITATION ACCOMPLISH ITS AIMS?}

Increased recognition and support for the geosciences is one of the most commonly cited rationales for pursuing accreditation. Yet, accrediting undergraduate curricula isn't likely to accomplish this aim even if all departments choose to develop accredited degrees. It is likely that many geoscience departments would simply opt out of a national accreditation system. Small departments already have some of the strongest educational programs and produce many students who go on to be highly successful in graduate programs. Many small departments are not large enough to cover all of the disciplines likely to be required by accreditation, and informal feedback suggests that many Research-1 departments would also undoubtedly forego accreditation-they have little to lose from non-participation because their graduates hold respected degrees from highly regarded universities. Accreditation might appeal to public institutions at regional and/or urban campuses where professional programs typically dominate, but costs required to comply with external accreditation standards could place such departments in jeopardy of program cuts or closure.

\section{ALTERNATIVES, CONCLUSIONS, AND NEXT STEPS}

Two directions offer promising alternatives to accreditation. The first is a growing movement to identify the ideas and concepts that characterize geoscience literacy and to publish this synthesis (Earth Science Literacy Initiative, www.earthscienceliteracy.org). The second is creation of community-developed standards (not accreditation), which might usefully include big ideas, skills, and modes of inquiry that lead to positive student learning outcomes and are of practical benefit in all geoscience careers.

Licensing of professional geologists is an important component for increasing public and political recognition and support for our science and profession, but such licensing should take place after the baccalaureate (National Association of State Boards of Geology, www.asbog.org). GSA's efforts would be well spent in promoting an increase in the number of states that require professional geologist licensure.

At the undergraduate level, no one wins with accreditation-not the students, not the departments, not the profession, not society. Challenges facing earth scientists are likely to change during students' careers, and we must educate them to be adaptable, broadbased thinkers, capable of solving complex problems and articulate solutions. The prescribed curriculum that typically comes with accreditation would eliminate departmental flexibility to tailor curricula and train students to address the planet's ever-changing problems in a local context.

Our opposition to accreditation differs significantly from the general response to the GSA survey (GSA ad hoc comm., 2008). We wonder if the result is due to a low response rate from academic geologists. We also note that the pro-accreditation preface of the survey must have biased the response. We urge the coalition of professional societies charged with developing an accreditation system to solicit a larger faculty response before moving forward, and we urge geoscience faculty to become involved in the debate on accreditation - the stakes are high and the future of our field depends on it. To register your agreement and concerns, please visit www.ipetitions.com/petition/geoscience.

\section{ACKNOWLEDGMENTS}

The authors thank Dave Fastovsky, Steve Johnston, and Anne Veeger for helpful reviews.

\section{REFERENCES CITED}

GSA Ad Hoc Committee on Accreditation, 2008, Report: GSA Ad Hoc Committee on Accreditation: GSA Today, v. 18, p. 64-67, doi: 10.1130/1052-5173(2008)18 [64:GAHCOA]2.0.CO;2.

Drummond, C.N., and Markin, J.M., 2008, An analysis of the Bachelor of Science in Geology degree as offered in the United States: Journal of Geoscience Education, v. 56, p. 113-119.

Earth Science Literacy Initiative, 2008: http://www.earthscienceliteracy.org (last accessed 4 Sept. 2008).

National Association of State Boards of Geology, 2008: http://www.asbog.org/ (last accessed 4 Sept. 2008).

National Governors Association and National Association of State Budget Officers, 2008, The Fiscal Survey of States: Washington, D.C., http://www.nasbo.org/ Publications/PDFs/Fiscal\%20Survey\%20of\%20the\%20States $\% 20 J u n e \%$ 202008.pdf, 66 p. 